\title{
Decline of Real Power Loss and Preservation of Voltage Stability by using Chirping Algorithm
}

\author{
K. Lenin ${ }^{1}$, B. Ravindhranath Reddy ${ }^{2}$, M. Surya Kalavathi ${ }^{3}$ \\ ${ }^{1}$ Research Scholar, JNTU, Hyderabad 500085 India \\ ${ }^{2}$ Deputy Executive Engineer, JNTU, Hyderabad 500085 India \\ ${ }^{3}$ Professor of Electrical and Electronics Engineering, JNTU, Hyderabad 500 085, India \\ email: gklenin@gmail.com
}

\begin{abstract}
In this paper, a newChirping Algorithm (CA) is developed based on the chirping behaviour of crickets for solving the reactive power optimization problem. It is based on the chirping behaviour of crickets (insect) found almost everywhere around the world. CA algorithm is utilized to enhance the search with good exploration and exploitation, because almost every algorithm has difficulty in reaching the optimal solution. The proposed Chirping Algorithm (CA) has been tested in standard IEEE 30, 57,118 bus test systems and simulation results show clearly the better performance of the proposed algorithm in reducing the real power loss and control variables are well within the limits.
\end{abstract}

Keywords: optimal reactive power, transmission loss, chirping algorithm

\section{Introduction}

The main objective of optimal reactive power dispatch (ORPD) problem is to minimize both the real power loss and bus voltage deviation. Various numerical methods like the gradient method [1]-[2], Newton method [3] and linear programming [4]-[7] have been adopted to solve the optimal reactive power dispatch problem. Both the gradient and Newton methods have the complexity in managing inequality constraints. The problem of voltage stability and collapse play a vital role in power system planning and operation [8]. Evolutionary algorithms such as genetic algorithm have been already proposed to solve the reactive power flow problem [9]-[11]. In [12],[13], Hybrid differential evolution algorithm and Biogeography Based algorithm is projected to solve the reactive power dispatch problem. In [14],[15], an improved fuzzy based method and evolutionary programming is used to solve the optimal reactive power dispatch problem. In [16],[17], the optimal reactive power flow problem is solved by integrating a genetic algorithm with a nonlinear interior point method and pattern algorithm is used to solve ac-dc optimal reactive power flow model with the generator capability limits. In [18],[19] a two-step approach and a programming based approach is used to solve the optimal reactive power dispatch problem. In [20] a probabilistic algorithm is utilized for optimal reactive power provision in hybrid electricity markets with uncertain loads. We propose new CA algorithm to enhance the search with good exploration and exploitation, because almost every algorithm suffer in some mode in reaching the optimal solution. Cricket is an insect which emit a peculiar sound that is commonly known as chirping. Though the male crickets usually chirp, some female crickets do as well [21][23].Generally cricket chirps for two main things, first one when they want to mate then they emit a calling chirp and it is fairly loud and it will attracts female crickets. And second one, they chirp as violent behaviour which is called as aggressive chirp. This violent chirp is a very loud trill and is formed to fight with other male crickets. The proposed CA algorithm has been evaluated in standard IEEE 30, 57,118 bus test systems. The simulation results show that our proposed methodology outperforms all the entitled reported algorithms in minimization of real power loss.

\section{Objective Function}

\subsection{Active power loss}

The objective of the reactive power dispatch is to minimize the active power loss in the transmission network, which can be described as follows: 


$$
F=P L=\sum_{k \in N b r} g_{k}\left(V_{i}^{2}+V_{j}^{2}-2 V_{i} V_{j} \cos \theta_{i j}\right)
$$

or

$$
F=P L=\sum_{i \in N g} P_{g i}-P_{d}=P_{\text {gslack }}+\sum_{i \neq s l a c k}^{N g} P_{g i}-P_{d}
$$

Where $g_{k}$ is the conductance of branch between nodes $i$ and $j$, Nbr is the total number of transmission lines in power systems. $P_{d}$ is the total active power demand, $P_{g i}$ is the generator active power of unit $i$, and $P_{\text {gsalck }}$ is the generator active power of slack bus.

\subsection{Voltage profile improvement}

For minimizing the voltage deviation in $\mathrm{PQ}$ buses, the objective function becomes:

$$
F=P L+\omega_{v} \times V D
$$

Where $\omega_{v}$ : is a weighting factor of voltage deviation.

$\mathrm{VD}$ is the voltage deviation given by:

$$
V D=\sum_{i=1}^{N p q}\left|V_{i}-1\right|
$$

\subsection{Equality Constraint}

The equality constraint of the ORPD problem is represented by the power balance equation, where the total power generation must cover the total power demand and the power losses:

$$
P_{G}=P_{D}+P_{L}
$$

This equation is solved by running Newton Raphson load flow method, by calculating the active power of slack bus to determine active power loss.

\subsection{Inequality Constraints}

The inequality constraints reflect the limits on components in the power system as well as the limits created to ensure system security. Upper and lower bounds on the active power of slack bus, and reactive power of generators:

$$
\begin{aligned}
& P_{\text {gslack }}^{\min } \leq P_{\text {gslack }} \leq P_{\text {gslack }}^{\max } \\
& Q_{g i}^{\min } \leq Q_{g i} \leq Q_{g i}^{\max }, i \in N_{g}
\end{aligned}
$$

Upper and lower bounds on the bus voltage magnitudes:

$$
V_{i}^{\min } \leq V_{i} \leq V_{i}^{\max }, i \in N
$$

Upper and lower bounds on the transformers tap ratios:

$$
T_{i}^{\min } \leq T_{i} \leq T_{i}^{\max }, i \in N_{T}
$$

Upper and lower bounds on the compensators reactive powers:

$$
Q_{c}^{\min } \leq Q_{c} \leq Q_{C}^{\max }, i \in N_{C}
$$

Where $\mathrm{N}$ is the total number of buses, $\mathrm{N}_{\mathrm{T}}$ is the total number of Transformers; $\mathrm{N}_{\mathrm{c}}$ is the total number of shunt reactive compensators. 


\section{Proposed Chirping Algorithm}

Based on the chirping characteristics of crickets and their movement in space for mating and aggression the Chirping Algorithm (CA) is formulated to solve the reactive power problem. Each cricket is presumed to be a solution in the exploration space and is categorized by its position in the exploration space. Out of the total cricket population, few of them are arbitrarilynominated as female populations. Crickets are presumed to be in two conditions. At first when the male cricket chirps for mating, the female crickets are seduced and other male crickets move away. The male and female crickets will mate and produce offspring. They move to a new-fangled place, which means they are taken to improvedpositions in the exploration space. The fascination is based on the loudness of the chirping sound .From the chirping rate the frequency and velocity of the sound is calculated. Secondly, when the cricket chirps for antagonism other male crickets are enticed and female crickets will move away. All crickets may not be chirping for antagonism. The algorithm assumes that the probability of a cricket, chirping for antagonism is $p$ which is between 0 and 1 . When a cricket chirps for antagonism, it is assumed that they arbitrarily walk to another male cricket and fight. The persuasive cricket takes the place of the solution and eliminates the loser cricket.

\subsection{Calculation of chirping rate}

Amos Emerson Dolbear, an American physicist and naturalist, calculated the relationship between air temperature and the rate at which crickets chirp.

The temperature $\left(T_{f}\right)$ in degrees Fahrenheit from the number of chirps per minute $\left(N_{c}\right)$ is calculated as,

$$
T_{f}=50+\frac{N_{c}-40}{4}
$$

And its reformulated to give the temperature in degrees Celsius $\left(T_{c}\right)$, is given by,

$$
T_{c}=10+\frac{N_{c}-40}{7}
$$

The chirping rate can be calculated in a certain temperature $T_{c}$ or $T_{f}$ is given by,

$$
N_{c}=\left(T_{c}-10\right) * 7+40
$$

Or

$$
N_{c}=\left(T_{f}-50\right) * 4+40
$$

And the frequency $F$ and velocity $V$ of the cricket's chirping is calculated based on the chirping rate $\mathrm{N}_{\mathrm{c}}$,

$$
\begin{aligned}
& F_{c}=N_{c} * \gamma \\
& V=F * \lambda
\end{aligned}
$$

Where, $\gamma$ is anarbitrary value and $\lambda \in[0,1]$ is the wavelength

The step size of each cricket is calculated as:

$$
\begin{aligned}
& \text { distance }=\frac{V}{F} \\
& \text { Step }=\beta * \text { distance } *(\text { position }- \text { Better position })
\end{aligned}
$$

Where $\beta=0.01$ is a constant value and position is the current position and Better position is the best position ever encountered by the cricket.

Then the cricket will move to the new position by using the following formula:

$$
\text { New position }=\text { position }+ \text { step size } * \gamma
$$


The equations (11)-(19) are used when the crickets chirp for mating and they change their step size according to the chirping rate, frequency, velocity and distance at a certain temperature. For easiness, it is presumed that when the crickets chirp for antagonism they move to new position using arbitrary walk.

\section{Procedure for - mating_chirp ( )}

Begin for every cricket,

1. Compute the Chirping rate $\mathrm{N}_{\mathrm{c}}$ of each cricket based on the temperature using equation (13) or (14)

2. Compute the new frequency $F$ and velocity $V$ of each cricket using equation (15) and (16);

3. Compute the step size using equation (17),(18)

4. Transfer each cricket to the new position using equation (19)

5. Return crickets in new position

End

\section{Procedure for - mating ( )}

1. For every Male crickets $m_{A}$ in their new position, arbitrarily choose a female cricket $f_{E}$

2. Arbitrarily choose a cut point in both $m_{A}$ and $f_{E}$.

3. Interchangethe genetic materials of both $m_{A}$ and $f_{E}$ with reference to their cut points to create two new offspring. This is Similar to crossover in Genetic algorithm.

4. Compute the fitness of the offspring.

5. Return the best of the two offspring and the parents as the new cricket position.

End

\section{Procedure for - aggr_chirp ()}

1. If rand $>P$ then arbitrarily walk to the new position

2. Compute the fitness of the cricket in the new position.

3. Pick the best cricket

4. Return the best cricket position)

End

\section{CA algorithm for solving optimal reactive power problem}

1. Set the cricket's position

2. Arbitrarily choose $\mathrm{k}$ crickets as female crickets

3. Compute the fitness of each cricket

4. Pick the best cricket $\mathrm{f}_{\text {best cricket }}$ with their position

5. Fixg $g_{\text {best_cricket }}$ as the existingf $f_{\text {best_cricket }}$ andin the initial generation $g_{\text {best_cricket }} f_{\text {best_cricket }}$

6. While (stoppingcriteria is not met)

Then

a. Chirp for mating - Procedure mating_chirp ( )

b. Allow male crickets to mate with female crickets - Procedure mating ( )

c. Chirp for antagonism with probability P - Procedure aggr_chirp ( )

d. Calculate the fitness

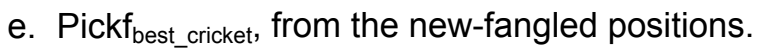

f. If $f_{\text {best_cricket }}>g_{\text {best_cricket }}$, then modernizeg ${ }_{\text {best_cricket }}$ with the existing $f_{\text {best_cricket }}$.

7. End while

8. Return the global best cricket at termination.

End

\section{Results and Discussion}

At first CA algorithm has been verified in IEEE 30-bus, 41 branch system. It has 6 generator-bus voltage magnitudes, 4 transformer-tap settings, and 2 bus shunt reactive compensators. Bus 1 is slack bus and 2, 5, 8, 11 and 13 are taken as PV generator buses and the rest are $P Q$ load buses. Control variables limits are listed in Table 1. 
Table 1. Preliminary Variable Limits (PU)

\begin{tabular}{lccc}
\hline \multicolumn{1}{c}{ Variables } & Min. & Max. & \multirow{2}{*}{ Type } \\
\hline Generator Bus & 0.92 & 1.12 & Continuous \\
Load Bus & 0.94 & 1.04 & Continuous \\
Transformer-Tap & 0.94 & 1.04 & Discrete \\
Shunt Reactive Compensator & -0.11 & 0.30 & Discrete \\
\hline
\end{tabular}

The power limits generators buses are represented in Table 2. Generators buses (PV) $2,5,8,11,13$ and slack bus is 1 .

Table 2. Generators Power Limits

\begin{tabular}{ccccc}
\hline Bus & Pg & Pgmin & Pgmax & Qgmin \\
\hline 1 & 98.00 & 51 & 202 & -21 \\
2 & 81.00 & 22 & 81 & -21 \\
5 & 53.00 & 16 & 53 & -16 \\
8 & 21.00 & 11 & 34 & -16 \\
11 & 21.00 & 11 & 29 & -11 \\
13 & 21.00 & 13 & 41 & -16 \\
\hline
\end{tabular}

Table 3. Values of Control Variables after Optimization

\begin{tabular}{cc}
\hline Control Variables & CA \\
\hline V1 & 1.0647 \\
V2 & 1.0462 \\
V5 & 1.0278 \\
V8 & 1.0279 \\
V11 & 1.0782 \\
V13 & 1.0589 \\
T4,12 & 0.00 \\
T6,9 9.01 \\
T6,10 & 0.01 \\
T28,27 & 0.90 \\
Q10 & 0.12 \\
Q24 & 0.12 \\
Real power loss & 4.2987 \\
Voltage deviation & 0.9082 \\
\hline
\end{tabular}

Table 3 shows the proposed approach succeeds in keeping the control variables within limits. Table 4 summarizes the results of the optimal solution obtained by various methods.

Table 4. Comparison Results

\begin{tabular}{cc}
\hline Methods & Real power loss (MW) \\
\hline SGA (24) & 4.98 \\
PSO (25) & 4.9262 \\
LP (26) & 5.988 \\
EP (26) & 4.963 \\
CGA (26) & 4.980 \\
AGA (26) & 4.926 \\
CLPSO (26) & 4.7208 \\
HSA (27) & 4.7624 \\
BB-BC (28) & 4.690 \\
CA & 4.2987 \\
\hline
\end{tabular}

Secondly the proposed hybrid CA algorithm is tested in standard IEEE-57 bus power system. The reactive power compensation buses are 18, 25 and 53. Bus 2, 3, 6, 8, 9 and 12 are PV buses and bus 1 is selected as slack-bus. The system variable limits are given in Table 5.

The preliminary conditions for the IEEE-57 bus power system are given as follows:

$$
P_{\text {load }}=12.422 \text { p.u. } Q_{\text {load }}=3.339 \text { p.u. }
$$

The total initial generations and power losses are obtained as follows: 


$$
\begin{aligned}
& \sum P_{G}=12.7729 \text { p.u. } \sum Q_{G}=3.4559 p . u . \\
& P_{\text {loss }}=0.27450 \text { p.u. } Q_{\text {loss }}=-1.2249 \text { p.u. }
\end{aligned}
$$

Table 6 shows the various system control variables i.e. generator bus voltages, shunt capacitances and transformer tap settings obtained after CA based optimization which are within the acceptable limits. In Table 7, shows the comparison of optimum results obtained from proposed CA with other optimization techniques. These results indicate the robustness of proposed CA approach for providing better optimal solution in case of IEEE-57 bus system.

Table 5. Variable limits

\begin{tabular}{cccccccc}
\hline \multicolumn{7}{c}{ Reactive Power Generation Limits } \\
\hline Bus no & 1 & 2 & 3 & 6 & 8 & 9 & 12 \\
\hline Qgmin & -1.4 & -.015 & -.02 & -0.04 & -1.3 & -0.03 & -0.4 \\
Qgmax & 1 & 0.3 & 0.4 & 0.21 & 1 & 0.04 & 1.50 \\
\hline \multicolumn{7}{c}{ Voltage And Tap Setting Limits } \\
\hline vgmin & vgmax & vpqmin & vpqmax & tkmin & tkmax \\
\hline 0.5 & 1.0 & 0.91 & 1.01 & 0.5 & 1.0 \\
\hline Bus no & \multicolumn{7}{c}{ Shunt Capacitor Limits } \\
\hline Qcmin & 18 & 25 & & 53 \\
Qcmax & 0 & 0 & 0 \\
\hline
\end{tabular}

Table 6. Control variables obtained after optimization

\begin{tabular}{cc}
\hline Control Variables & CA \\
\hline V1 & 1.1 \\
V2 & 1.069 \\
V3 & 1.057 \\
V6 & 1.032 \\
V8 & 1.034 \\
V9 & 1.028 \\
V12 & 1.032 \\
Qc18 & 0.0798 \\
Qc25 & 0.248 \\
Qc53 & 0.0589 \\
T4-18 & 1.010 \\
T21-20 & 1.078 \\
T24-25 & 0.978 \\
T24-26 & 0.949 \\
T7-29 & 1.083 \\
T34-32 & 0.957 \\
T11-41 & 1.010 \\
T15-45 & 1.059 \\
T14-46 & 0.917 \\
T10-51 & 1.030 \\
T13-49 & 1.059 \\
T11-43 & 0.917 \\
T40-56 & 0.903 \\
T39-57 & 0.957 \\
T9-55 & 0.967 \\
\hline
\end{tabular}


Table 7. Comparison results

\begin{tabular}{clccc}
\hline S.No. & \multicolumn{1}{c}{$\begin{array}{c}\text { Optimization } \\
\text { Algorithm }\end{array}$} & $\begin{array}{c}\text { Finest } \\
\text { Solution }\end{array}$ & $\begin{array}{c}\text { Poorest } \\
\text { Solution }\end{array}$ & $\begin{array}{c}\text { Normal } \\
\text { Solution }\end{array}$ \\
\hline 1 & NLP [29] & 0.25902 & 0.30854 & 0.27858 \\
2 & CGA [29] & 0.25244 & 0.27507 & 0.26293 \\
3 & AGA [29] & 0.24564 & 0.26671 & 0.25127 \\
4 & PSO-w [29] & 0.24270 & 0.26152 & 0.24725 \\
5 & PSO-cf [29] & 0.24280 & 0.26032 & 0.24698 \\
6 & CLPSO [29] & 0.24515 & 0.24780 & 0.24673 \\
7 & SPSO-07 [29] & 0.24430 & 0.25457 & 0.24752 \\
8 & L-DE [29] & 0.27812 & 0.41909 & 0.33177 \\
9 & L-SACP-DE [29] & 0.27915 & 0.36978 & 0.31032 \\
10 & L-SaDE [29] & 0.24267 & 0.24391 & 0.24311 \\
11 & SOA [29] & 0.24265 & 0.24280 & 0.24270 \\
12 & LM [30] & 0.2484 & 0.2922 & 0.2641 \\
13 & MBEP1 [30] & 0.2474 & 0.2848 & 0.2643 \\
14 & MBEP2 [30] & 0.2482 & 0.283 & 0.2592 \\
15 & BES100 [30] & 0.2438 & 0.263 & 0.2541 \\
16 & BES200 [30] & 0.3417 & 0.2486 & 0.2443 \\
17 & Proposed CA & 0.22298 & 0.23102 & 0.23115 \\
\hline
\end{tabular}

Then CA has been tested in standard IEEE 118-bus test system [24] .The system has 54 generator buses, 64 load buses, 186 branches and 9 of them are with the tap setting transformers. The limits of voltage on generator buses are 0.95,-1.1 per-unit., and on load buses are $0.95,-1.05$ per-unit. The limit of transformer rate is $0.9,-1.1$, with the changes step of 0.025 . The limitations of reactive power source are listed in Table 8, with the change in step of 0.01 .

Table 8. Limitation of reactive power sources

\begin{tabular}{cccccccc}
\hline BUS & 5 & 34 & 37 & 44 & 45 & 46 & 48 \\
\hline QCMAX & 0 & 14 & 0 & 10 & 10 & 10 & 15 \\
QCMIN & -40 & 0 & -25 & 0 & 0 & 0 & 0 \\
BUS & 74 & 79 & 82 & 83 & 105 & 107 & 110 \\
QCMAX & 12 & 20 & 20 & 10 & 20 & 6 & 6 \\
QCMIN & 0 & 0 & 0 & 0 & 0 & 0 & 0 \\
\hline
\end{tabular}

In this case, the number of population is increased to 120 to explore the larger solution space. The total number of generation times is set to 200 . The statistical comparison results of 50 trial runs have been list in Table 9 and the results clearly show the better performance of proposed algorithm.

Table 9. Comparison results

\begin{tabular}{ccccc}
\hline $\begin{array}{c}\text { Active power } \\
\text { loss (p.u) }\end{array}$ & $\begin{array}{c}\text { BBO } \\
{[32]}\end{array}$ & $\begin{array}{c}\text { ILSBBO/ } \\
\text { strategy1 [32] }\end{array}$ & $\begin{array}{c}\text { ILSBBO/ } \\
\text { strategy1 [32] }\end{array}$ & $\begin{array}{c}\text { Proposed } \\
\text { CA }\end{array}$ \\
\hline $\min$ & 128.77 & 126.98 & 124.78 & 120.06 \\
$\max$ & 132.64 & 137.34 & 132.39 & 129.05 \\
Average & 130.21 & 130.37 & 129.22 & 122.89 \\
\hline
\end{tabular}

\section{Conclusion}

Chirping Algorithm has been successfully applied for Optimal Reactive Power dispatch problem.Chirping Algorithm based optimal reactive power problem has been tested in standard IEEE30, 57,118 bus systems. Performance comparisons with standard population-based algorithms have given inspiring results. Real power loss has been significantlyabridged and control variables are well within the limits.Chirping Algorithmarisesefficaciously to find good solutions when compared to that of other algorithms. The simulation results presented in preceding section prove the capability ofChirping Algorithm method to reach at near global optimal solution. 


\section{References}

[1] O. Alsac, B. Scott. Optimal load flow with steady state security. IEEE Transaction. 1973; PAS: 745751.

[2] Lee KY, Paru YM, Oritz JL. A united approach to optimal real and reactive power dispatch. IEEE Transactions on power Apparatus and systems. 1985; PAS-104: 1147-1153.

[3] A. Monticelli, MVF. Pereira, S. Granville. Security constrained optimal power flow with post contingency corrective rescheduling. IEEE Transactions on Power Systems. 1987; PWRS-2(1): 175182.

[4] Deeb N, Shahidehpur SM. Linear reactive power optimization in a large power network using the decomposition approach. IEEE Transactions on power system. 1990; 5(2): 428-435.

[5] E. Hobson. Network consrained reactive power control using linear programming. IEEE Transactions on power systems. 1980; PAS -99(4): 868-877.

[6] KY. Lee, YM. Park, JL. Oritz. Fuel -cost optimization for both real and reactive power dispatches. IEE Proc. 131C(3): 85-93.

[7] MK. Mangoli, KY. Lee. Optimal real and reactive power control using linear programming. Electr. Power Syst. Res. 1993; 26: 1-10.

[8] CA. Canizares, ACZ. de Souza, VH. Quintana. Comparison of performance indices for detection of proximity to voltage collapse. 1996; 11(3): 1441-1450.

[9] SR. Paranjothi, K. Anburaja. Optimal power flow using refined genetic algorithm. Electr. Power Compon. Syst. 2002; 30: 1055-1063.

[10] D. Devaraj, B. Yeganarayana. Genetic algorithm based optimal power flow for security enhancement. IEE proc-Generation.Transmission and. Distribution. 6 November 2005: 152.

[11] A. Berizzi, C. Bovo, M. Merlo, M. Delfanti. A ga approach to compare orpf objective functions including secondary voltage regulation. Electric Power Systems Research. 2012; 84(1): 187 - 194.

[12] CF. Yang, GG. Lai, CH. Lee, CT. Su, GW. Chang. Optimal setting of reactive compensation devices with an improved voltage stability index for voltage stability enhancement. International Journal of Electrical Power and Energy Systems. 2012; 37(1): 50 - 57.

[13] P. Roy, S. Ghoshal, S. Thakur. Optimal var control for improvements in voltage profiles and for real power loss minimization using biogeography based optimization. International Journal of Electrical Power and Energy Systems. 2012; 43(1): 830 - 838.

[14] B. Venkatesh, G. Sadasivam, M. Khan. A new optimal reactive power scheduling method for loss minimization and voltage stability margin maximization using successive multi-objective fuzzy Ip technique. IEEE Transactions on Power Systems. 2000; 15(2): 844-851.

[15] W. Yan, S. Lu, D. Yu. A novel optimal reactive power dispatch method based on an improved hybrid evolutionary programming technique. IEEE Transactions on Power Systems. 2004; 19(2): 913-918.

[16] W. Yan, F. Liu, C. Chung, K. Wong. A hybrid genetic algorithminterior point method for optimal reactive power flow. IEEE Transactions on Power Systems. 2006; 21(3): 1163-1169.

[17] J. Yu, W. Yan, W. Li, C. Chung, K. Wong. An unfixed piecewiseoptimal reactive power-flow model and its algorithm for ac-dc systems. IEEE Transactions on Power Systems. 2008; 23(1): $170-176$.

[18] F. Capitanescu. Assessing reactive power reserves with respect to operating constraints and voltage stability. IEEE Transactions on Power Systems. 2011; 26(4): 2224-2234.

[19] Z. Hu, X. Wang, G. Taylor. Stochastic optimal reactive power dispatch: Formulation and solution method. International Journal of Electrical Power and Energy Systems. 2010; 32(6): 615 - 621.

[20] A. Kargarian, M. Raoofat, M. Mohammadi. Probabilistic reactive power procurement in hybrid electricity markets with uncertain loads. Electric Power Systems Research. 2012; 82(1): 68-80.

[21] Lorenz, K, N. Tinbergen. Behavior of the House Cricket. Achetadomesticus. 2010.

[22] William D. Brown, Adam T. Smith, BM., JG. Aggressive contests in house crickets: size, motivation and the information content of aggressive songs. Animal Behaviour. Elsevier. 2006; 72: 225-233.

[23] Jonti Deuri, S. Siva Sathya. A Novel Cricket Chirping Algorithm for Engineering Optimization Problem. Advances in Natural and Applied Sciences. 2015; 9(6): 397-402.

[24] IEEE. The IEEE 30-bus test system and the IEEE 118-test system. 1993. http://www.ee.washington.edu/trsearch/pstca/. 